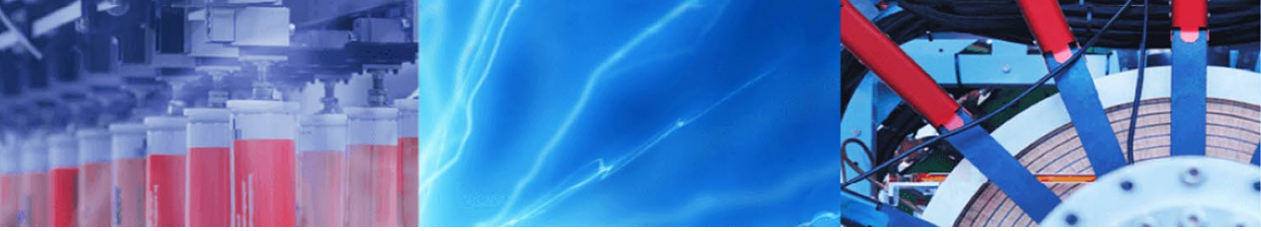

Research Article

\title{
Influence of surface roughness on the morphology of interfacial layer and on out-burst formation during hot-dip galvanizing
}

\author{
Zhanpeng Gong ${ }^{1} \cdot$ Yimin Gao $^{1} \cdot$ Xiaoyu Huang ${ }^{1}$
}

Received: 17 January 2020 / Accepted: 27 February 2020 / Published online: 4 March 2020

(c) Springer Nature Switzerland AG 2020

\begin{abstract}
This work studied the morphology of the interfacial layers formed on the substrates with different surface roughness in a bath containing $0.3 \mathrm{wt} \% \mathrm{Al}$ at $460^{\circ} \mathrm{C}$. The immersion time was set to $8 \mathrm{~s}, 60 \mathrm{~s}, 180 \mathrm{~s}, 300 \mathrm{~s}, 600 \mathrm{~s}, 1200 \mathrm{~s}$, and $1800 \mathrm{~s}$, respectively. The as-prepared samples were characterized by the 3D laser scanning microscope, the grazing incident $X$-ray diffraction, the field emission scanning electron microscope, the inductively-coupled plasma mass spectrometry, the transmission electron microscope, and the electron back-scattered diffraction. The results showed that the morphology and the crystal orientation of the interfacial layer varied significantly with the change of surface roughness. $A$ thick, compact mono-orientated interfacial layer was formed on the substrate with $\mathrm{Ra}=0.031 \mu \mathrm{m}$ and no out-burst was observed even for an $1800 \mathrm{~s}$ immersion. However, the thinner, discrete interfacial layers with the randomly-distributed orientation were formed on the substrate with $\mathrm{Ra}=0.455 \mu \mathrm{m}$ and $0.112 \mu \mathrm{m}$ and the out-burst appeared for less than $60 \mathrm{~s}$ immersion. The mechanism of the out-burst formation also changed with the surface roughness. For $\mathrm{Ra}=0.455 \mu \mathrm{m}$, the out-burst emerged along the grooves, but it only appeared in certain areas for $\mathrm{Ra}=0.112 \mu \mathrm{m}$.
\end{abstract}

Keywords Surface roughness · Interfacial layer · Out-burst · Crystal orientation · Continuous hot dip galvanizing

\section{Introduction}

Galvanized steel is vital for applications where corrosion protection is needed, such as for automotive body parts, power transmission system, and for highway infrastructure. Continuous hot-dip galvanizing has distinct advantages over other methods because it is a relatively lowcost, high-volume process [1]. The mechanical properties of the galvanizing coating are very important and depend on the microstructure of the interface between the substrate and the overlay $[2,3]$. In practice, a small amount of $\mathrm{Al}(0.1-0.3 \mathrm{wt} \%)$ is added to the molten zinc bath to form an extremely thin $\mathrm{Fe}_{2} \mathrm{Al}_{5} \mathrm{Zn}_{x}(0<x<1)$ intermetallic interfacial layer between the steel substrate and the zinc coating $[4,5]$. The layer acts as a barrier to inhibit the inward diffusion of Zinc which leads to the generation of brittle Fe-Zn compounds that deteriorate the adhesion and formability of the coating $[6,7]$. Hence, the good mechanical properties of the coating come form a good performance of the so called 'inhibition layer'.

The morphology and crystal orientation of interfacial layer plays a key role in the inhibition of the Fe-Zn reaction. The out-burst is easily to generate on the discrete, thin randomly-oriented layer as it has a higher inward diffusion rate of Zinc. The mono-oriented layer has a lower percentage of high angle grain boundary, thus, the inward diffusion rate of Zinc in this layer is lower. Owing to the lower diffusion rate and the longer diffusion path of Zinc, the incubation period of the out-burst in the thick and compact layer is longer [8-10]. The typical interfacial layer

$\triangle$ Zhanpeng Gong, msegzp@foxmail.com; $\bowtie$ Yimin Gao, ymgao@xjtu.edu.cn | ${ }^{1}$ State Key Laboratory for Mechanical Behavior of Materials, School of Materials Science and Engineering, Xi'an Jiaotong University, No. 28, Xianning West Road, Xi'an 710049, Shaanxi Province, People's Republic of China. 
formed within a few seconds is about $100 \mathrm{~nm}$ thick and the grain size of $\mathrm{Fe}_{2} \mathrm{Al}_{5}$ is about $50 \mathrm{~nm}$, which is attributed to the small critical nucleation energy of $\mathrm{Fe}_{2} \mathrm{Al}_{5}[11,12]$. There are some specific orientation relationships between the a-Fe and the $\mathrm{Fe}_{2} \mathrm{Al}_{5}$ crystal and the iron is a suitable heterogeneous nucleation site $[13,14]$. Therefore, the epitaxial $\mathrm{Fe}_{2} \mathrm{Al}_{5}$ grains formed on the same matrix crystal are in a similar orientation and with a similar morphology [9, 10]. It is well accepted that the reaction during the hotdip galvanization which has the Al-containing Zinc bath can be broken into four steps. The first step is the dissolution of matrix, which is followed by the nucleation of $\mathrm{Fe}_{2} \mathrm{Al}_{5}$ on the matrix surface. Then, the diffusion-controlled growth of the $\mathrm{Fe}_{2} \mathrm{Al}_{5}$ layer after the surface is completely covered. Owing to the very high nucleation rate of $\mathrm{Fe}_{2} \mathrm{Al}_{5}$, the inward diffusion of Zinc is assumed to take place after the matrix surface is covered $[11,12,15]$. The first two steps have remarkable influences on the morphology of the interfacial layer in the early stage and the inward diffusion rate of Zinc is determined by the morphology of the interfacial layer $[9,16-18]$. The effects of the substrate chemical composition $[16,19,20]$, the Al concentration of the $\mathrm{Zn}$ bath [8], the substrate grain size [10], the temperature $[8,11]$, and the reaction time [17] on the morphology of the interfacial layer and on the inward diffusion of Zinc have been determined.

In the modern continuous hot-dip galvanizing industry, the surface roughness ( $\mathrm{Ra}$ ) of the steel is in the range of few microns to tens of nanometers. The out-burst is prone to generate during the immersion, so the effectiveness of the interfacial layer is important. However, the influences of the substrate surface roughness on the morphology of the interfacial layer and on the out-burst formation are not yet fully understood. Therefore, the investigation of them will show a general significance on the improvement of the hot-dip galvanizing process.

\section{Experimental details}

The industry pure iron was cut into the size of $70 \times 10 \times 2 \mathrm{~mm}$ and they were polished by waters abrasive papers with no. 240, 2000, and 2000 in the last step. Then, the samples were labeled $G 1, G 2$, and $P$, respectively. The sample $P$ was further polished with 2.5 and $0.5 \mu \mathrm{m}$ diamond paste. All the samples were degreased with a $3 \mathrm{wt} \%$ $\mathrm{NaOH}$ aqueous solution at $80^{\circ} \mathrm{C}$ for $20 \mathrm{~min}$, then they were flushed with deionized water. A $50 \mathrm{wt} \%$ aqueous solution of $\mathrm{ZnCl}_{2}$ and $\mathrm{NH}_{4} \mathrm{Cl}$ at the 1:3 molar ratio was used for the fluxing $\left(60^{\circ} \mathrm{C}, 90 \mathrm{~s}\right)$ treatment. This process was adopted for all samples. After the samples were dried in forced air for $90 \mathrm{~s}$, they were immersed in a $0.3 \mathrm{wt} \%$ Al-containing liquid zinc immediately for 8 s, 60 s, 180 s, 300 s, 600 s,
$1200 \mathrm{~s}$, and $1800 \mathrm{~s}$, respectively. Then, the samples were quenched in water.

The 3D laser scanning microscope (Keyence VK-9700, $1000 \mathrm{X}$ ) was used to measure the surface roughness of the polished, fluxed, and cleaned substrates. In the present study, we used the arithmetical mean deviation of the profile, Ra, to quantify the surface roughness. In order to improve the measuring accuracy, six regions were measured in each specimen. We performed the GIXRD at the incident angle of $0.5^{\circ}$ on the Bruker D8 ADVANCE X-ray diffractometer with the $\mathrm{Cu} \mathrm{K}_{\mathrm{a}}$ radiation $\left(\lambda_{\mathrm{Cu}}=0.154 \mathrm{~nm}\right)$ to obtain the phase information about the interfaces. The samples for the microstructural characterization were cut to a size of $10 \times 10 \times 2 \mathrm{~mm}$ from the center area of the galvanized steel. We used the FE-SEM (Zeiss Gemini SEM 500, at $15 \mathrm{kV}$ ) to study the morphology of the interfacial layers. The Al content of the interfacial layers was measured by ICP-MS (PE NexION 350D). The TEM observation allowed us to study the crystal orientation and the morphology of the interfacial layer. The samples were carefully grinded to about $50 \mu \mathrm{m}$ thick. Then, they were dipped into a solution of nitric acid and ethanol in a 1:19 volume ratio for $30 \mathrm{~min}$ to eliminate the iron matrix. The interfacial layers were placed on the copper grid for the TEM observation (JEM$200 C X, 120 \mathrm{kV}$ ). We used the EBSD to study the interface crystal orientation of the cross-section of the galvanized samples. The samples ( $G 1, G 2$, and $P$ with an 8 s immersion) were finely polished with the vibration polishing (Buehler VibroMet 2 Vibratory Polisher). We used the detector (HKLNordlysNano) in the SEM (Hitachi SU3500) for the EBSD analyses. The acceleration voltage of $25 \mathrm{kV}$ and the step size of $0.015 \mu \mathrm{m}$ were adopted throughout the study.

\section{Results and discussion}

Figure 1 shows the surface morphology of sample G1, $\mathrm{G} 2$, and $\mathrm{P}$ which had been polished, fluxed and cleaned. The values of the resulting average surface roughness (Ra) for sample $G 1, G 2$, and P were $0.455 \pm 0.013 \mu \mathrm{m}$, $0.112 \pm 0.011 \mu \mathrm{m}$, and $0.031 \pm 0.007 \mu \mathrm{m}$, respectively. The value of the surface roughness and its standard deviation decreased with the application of the finer polishing.

The GIXRD pattern of sample $P$ with an 8-s immersion is shown in Fig. 2a. Even though the incident angle was low $\left(0.5^{\circ}\right)$, the matrix ( $\left.\mathrm{a}-\mathrm{Fe}\right)$ was also detected. Meanwhile, the other measured peaks were in consistent with the $\mathrm{Fe}_{2} \mathrm{Al}_{5}$, which signified that only $\mathrm{Fe}_{2} \mathrm{Al}_{5}$ was formed on the interface. Due to the small thickness of the interfacial layer and the high surface roughness of the matrix, the GIXRD patterns of sample $\mathrm{G} 1$ and $\mathrm{G} 2$ after an 8-s immersion were too obscure to reveal any useful information. So they were not presented here. 

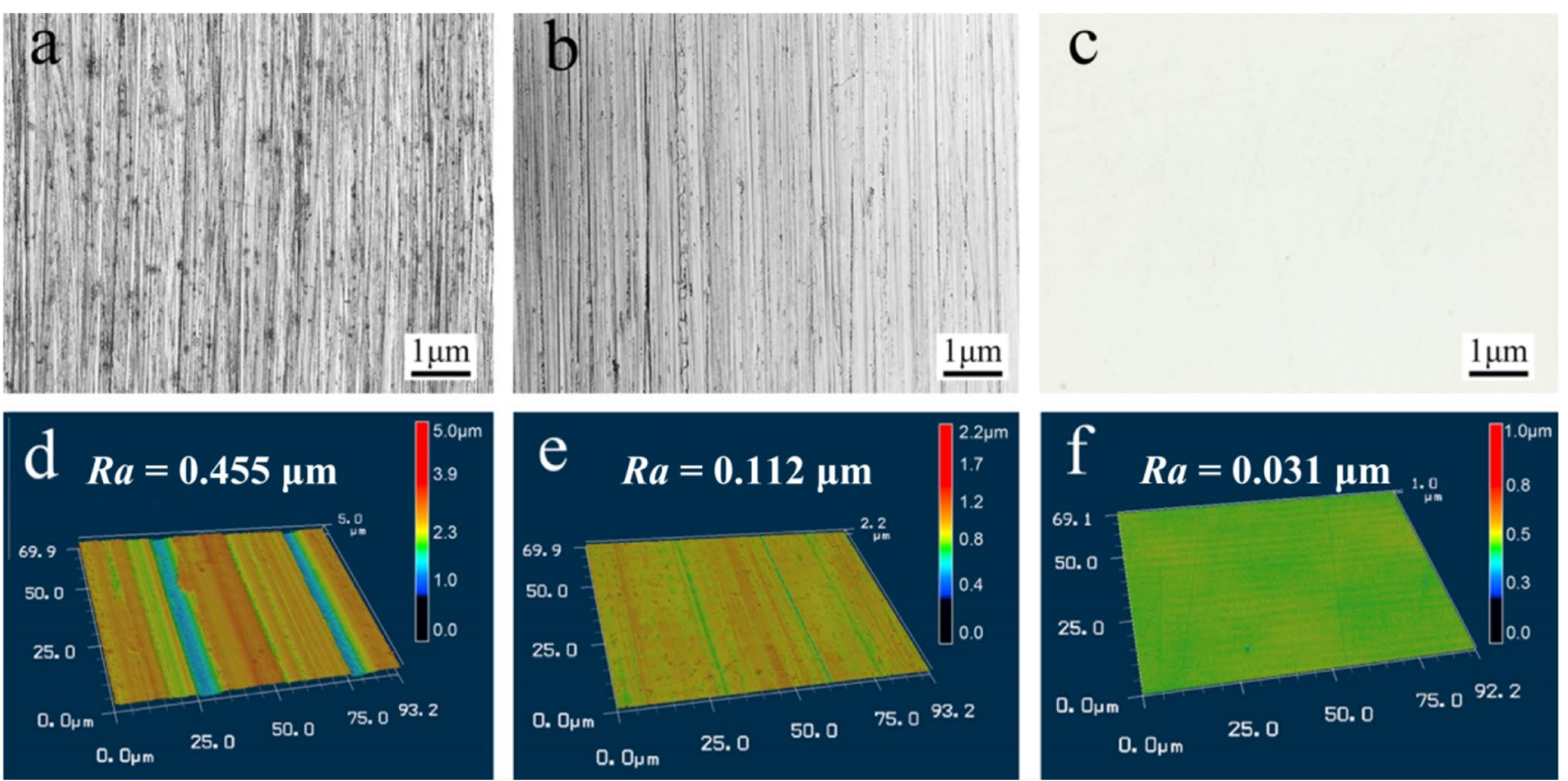

Fig. 1 Optical micrographs and 3D images of the surface of the polished substrates (industrial pure iron). Optical microstructure for a $\mathrm{Ra}=0.455 \mu \mathrm{m}, \mathbf{b} \mathrm{Ra}=0.112 \mu \mathrm{m}$, and $\mathbf{c} \mathrm{Ra}=0.031 \mu \mathrm{m}$. 3D images for $\mathbf{d} \mathrm{Ra}=0.455 \mu \mathrm{m}, \mathbf{e} \mathrm{Ra}=0.112 \mu \mathrm{m}$, and $\mathbf{f} \mathrm{Ra}=0.031 \mu \mathrm{m}$
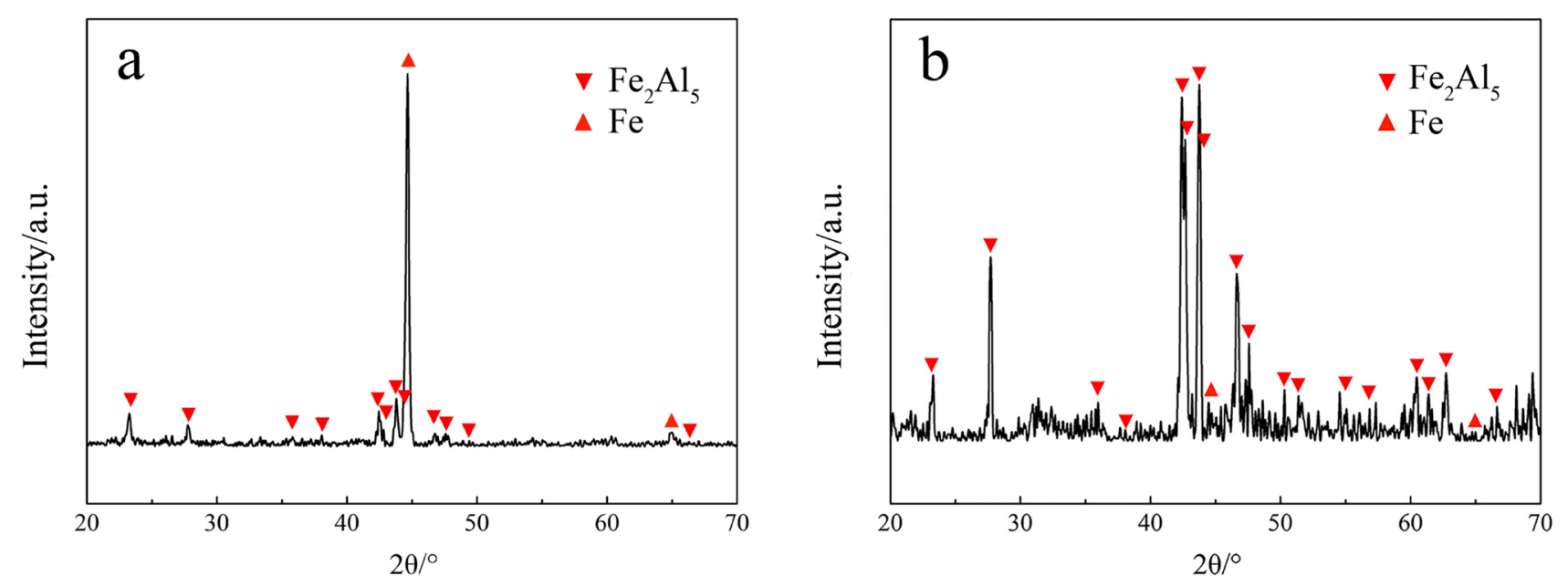

Fig. 2 X-ray diffraction patterns of the interfaces of $\mathbf{a}$ the sample with $\mathrm{Ra}=0.031 \mu \mathrm{m}$ and an 8 -s immersion and $\mathbf{b}$ the sample with $\mathrm{Ra}=0.112 \mu \mathrm{m}$ and a 60-s immersion

Figure 3 shows the morphology of the cross-section $(a-c)$ and the top-view $(d-f)$ of the interfacial layers after an 8-s immersion. The uniform and continuous interfacial layers were formed in all samples. It could be seen in Fig. 3a-c that the thickness of the interfacial layer increased when the surface roughness of the matrix decreased. The thickness of the interfacial layer can be determined by assuming that the layer is compact $\mathrm{Fe}_{2} \mathrm{Al}_{5}$ and the surface density of the $\mathrm{Al}$ atom is proportional to the thickness of the interfacial layer. Therefore, the thickness of the interfacial layer can be determined by $[9,12]$ :

$$
\rho_{\text {sur }}=\frac{M_{\mathrm{Al}}}{\mathrm{A}}
$$

$1 \mathrm{mg} \mathrm{m}^{-2} \mathrm{Al}=0.44 \mathrm{~nm} \mathrm{Fe}_{2} \mathrm{Al}_{5}$

$\mathrm{d}=0.44 \rho_{\text {sur }}$ 

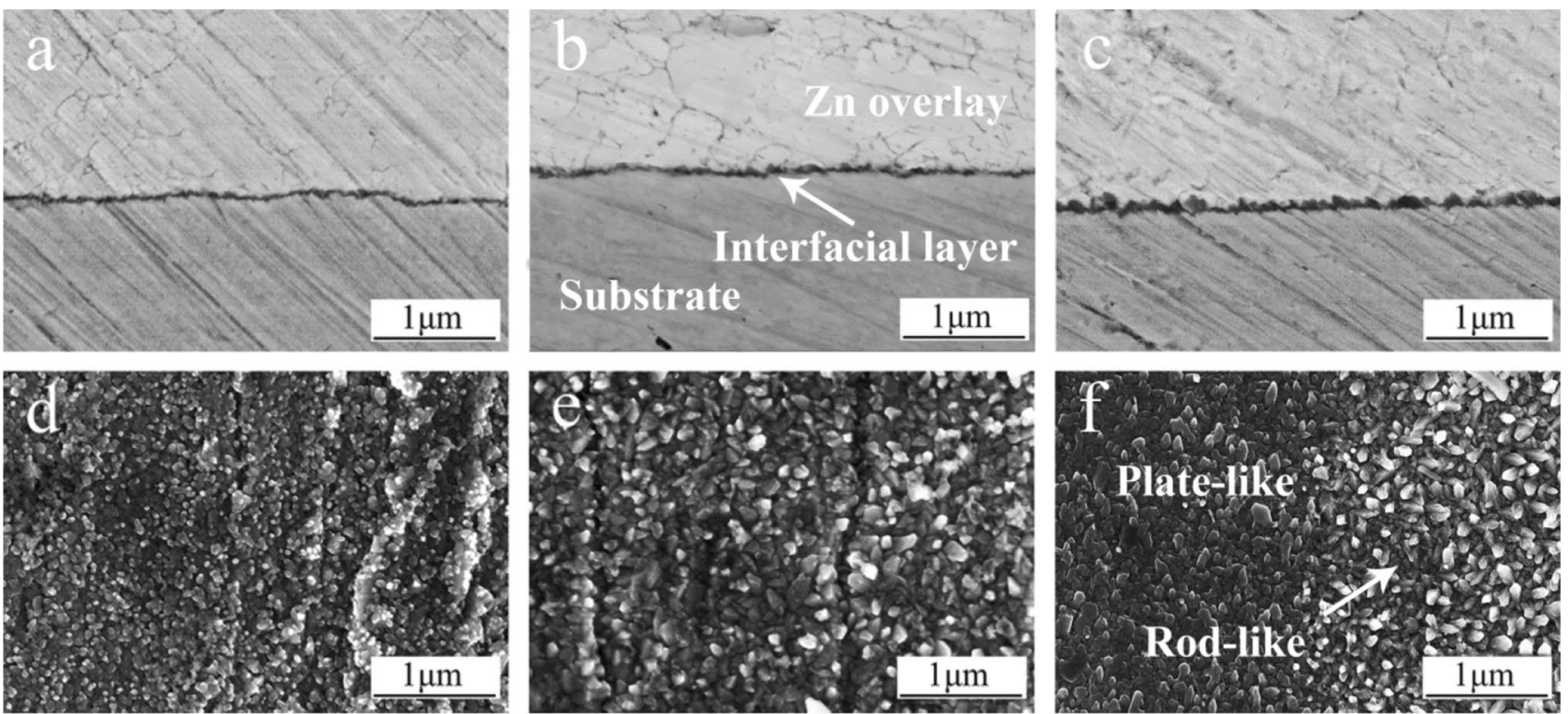

Fig. 3 Morphology of the interfacial layers obtained in a Zinc bath containing $0.3 \mathrm{wt} \% \mathrm{Al}$ with an 8-s immersion. BSE images of the cross-section of samples with a $\mathrm{Ra}=0.455 \mu \mathrm{m}, \mathbf{b} \mathrm{Ra}=0.112 \mu \mathrm{m}$,

where $\rho_{\text {sur }}$ is the surface density $\left(\mathrm{mg} \mathrm{m}^{-2}\right)$ of $\mathrm{Al}, \mathrm{M}_{\mathrm{Al}}$ is the Al weight (mg) measured by ICP-MS. A is the surface area $\left(\mathrm{m}^{-2}\right)$ of the sample and dis the thickness of the interfacial layer $(\mathrm{nm})$. The estimated thickness $(\mathrm{d})$ of the interfacial layers for sample $\mathrm{G} 1, \mathrm{G} 2$ and $\mathrm{P}$ were $50 \mathrm{~nm}, 90 \mathrm{~nm}$, and $140 \mathrm{~nm}$, respectively. The results agreed well with what is shown in Fig. $2 \mathrm{a}-\mathrm{c}$. It meant that the surface roughness had a significant influence on the thickness of the interfacial layer which was formed with an 8-s immersion.

It is indicated in Fig. $3 \mathrm{~d}-\mathrm{f}$ that the morphology of the interfacial layer varies in different samples. The $\mathrm{Fe}_{2} \mathrm{Al}_{5}$ crystals of sample $\mathrm{G} 1$ were small (about $50 \mathrm{~nm}$ ) and euqiaxed. As the surface roughness decreased, the $\mathrm{Fe}_{2} \mathrm{Al}_{5}$ crystals became larger and significantly elongated. The morphology of the $\mathrm{Fe}_{2} \mathrm{Al}_{5}$ crystals was almost identical all over the interface for sample $\mathrm{G} 1$ and $\mathrm{G} 2$. However, the morphology in different regions of sample $\mathrm{P}$ was distinct. Some areas mainly consisted of the plate-like crystals. Meanwhile, the rod-like crystals were predominant in the coterminous area.

The TEM bright-field images of the interfacial layers of samples G1, G2, and P after an 8-s immersion are shown in Fig. 4. As the surface roughness decreased, the interfacial layer became more compact and the grain size of $\mathrm{Fe}_{2} \mathrm{Al}_{5}$ increased, which corresponds to what is seen in the Fig. 3d-f. For sample G1, the interfacial layer became thinner in the spots which corresponded to the grooves of the matrix surface and the gaps were found here, as seen in the Fig. $4 \mathrm{a}$, d. In sample $\mathrm{G} 2$, the $\mathrm{Fe}_{2} \mathrm{Al}_{5}$ crystals became larger and more elongated in the certain domains and the and $\mathbf{c} R a=0.031 \mu \mathrm{m}$. SE images of the top-view of samples with $\mathbf{d}$ $\mathrm{Ra}=0.455 \mu \mathrm{m}$, e $\mathrm{Ra}=0.112 \mu \mathrm{m}$, and $\mathbf{f} \mathrm{Ra}=0.031 \mu \mathrm{m}$

holes were found at these locations. However, the layer around them was still compact with the smaller grain size, as seen in Fig. 4b, e. The sample P had the largest average grain size and the most compact layer. Moreover, as it was seen in Fig. 4c, $f$ that the interfacial layer of sample $P$ was divided into several parts. In the given part of the interfacial layer, the morphology of the $\mathrm{Fe}_{2} \mathrm{Al}_{5}$ crystals was almost identical but it changed in other parts (Fig. 6f), which shows a good agreement to the Fig. $3 f$.

Figure 5 shows the TEM dark-field images of the interfacial layers of samples $G 1, G 2$, and $P$ after an 8-s immersion. In the TEM dark-field imaging, the crystals with the selected orientation appear brighter, so the crystals with the identical orientation can be conveniently recognized. For sample G1 and G2 (Fig. 5a, b), the orientation of the $\mathrm{Fe}_{2} \mathrm{Al}_{5}$ crystals was distributed randomly. However, in sample $\mathrm{P}$, the $\mathrm{Fe}_{2} \mathrm{Al}_{5}$ crystals had an identical orientation in the given part (Fig. $5 \mathrm{c}$ ). It can be seen in Figs. 4c, f, and $5 \mathrm{c}$ (sample $P$ ) that the orientation of the parts which possess the almost identical morphology is same.

The crystal orientation of the interfaces of sample G1, $\mathrm{G} 2$, and $\mathrm{P}$ (cross-section) with an 8-s immersion were characterized by EBSD. The distribution of the crystal orientation is shown in Fig. 6. The EBSD patterns were analyzed for three possible phases, namely a-Fe, $\mathrm{Fe}_{2} \mathrm{Al}_{5}$, and $\mathrm{Zn}$, but only the a-Fe was identified in all samples. Owing to the different mechanical polishing processes, the surfaces of the substrates experienced the varying degree of the distortion. For sample G1 (Fig. 6a), the surface grains were smashed into many randomly-oriented small crystals. The

\section{SN Applied Sciences}



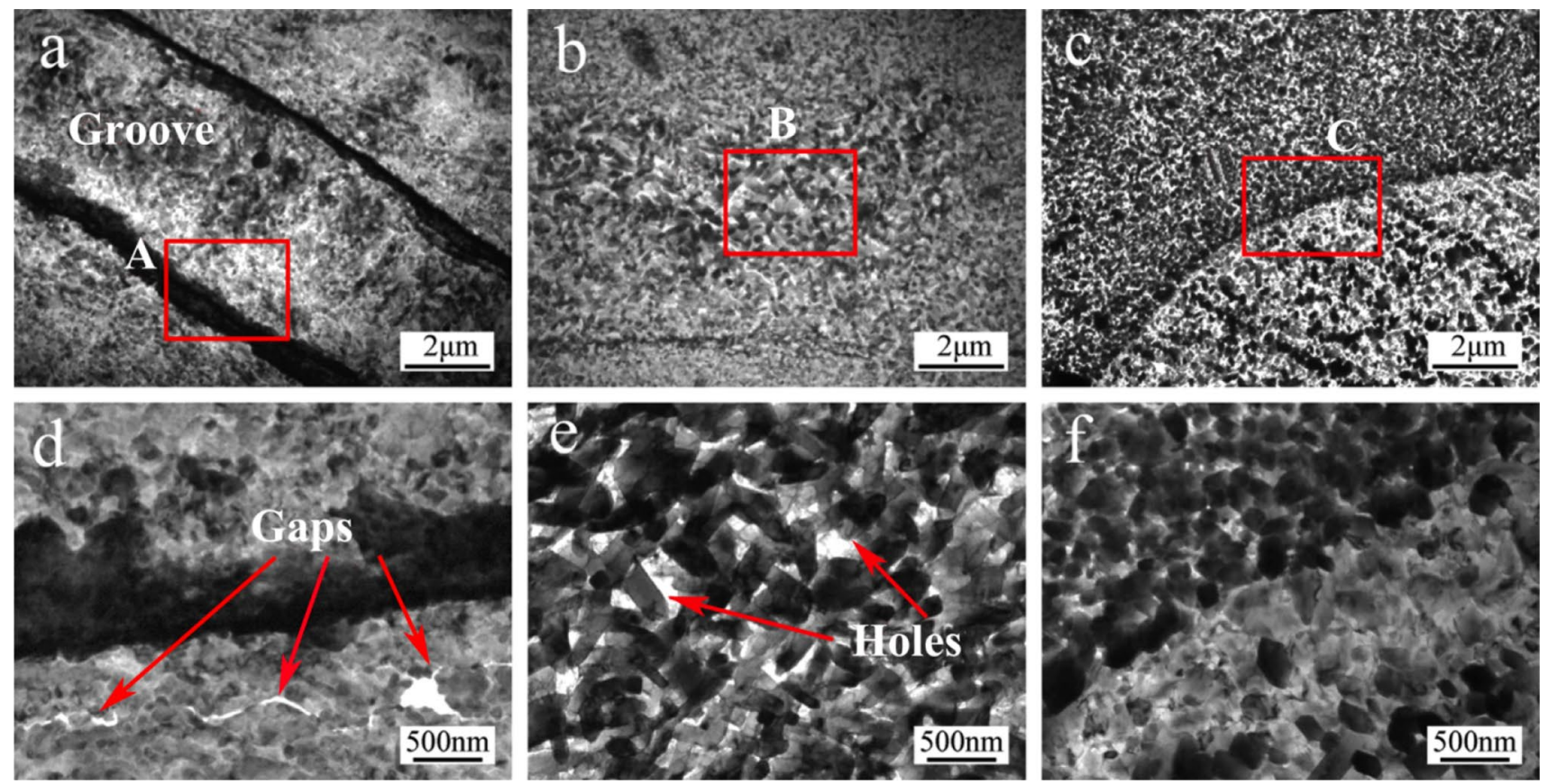

Fig. 4 TEM bright-field images of the interfacial layers after an 8-s immersion for $\mathbf{a} \operatorname{Ra}=0.455 \mu \mathrm{m}, \mathbf{b} \mathrm{Ra}=0.112 \mu \mathrm{m}, \mathbf{c} \mathrm{Ra}=0.031 \mu \mathrm{m}$, and $\mathbf{d}$ area $A$, e area $B$, and $\mathbf{f}$ area $C$, at high magnification
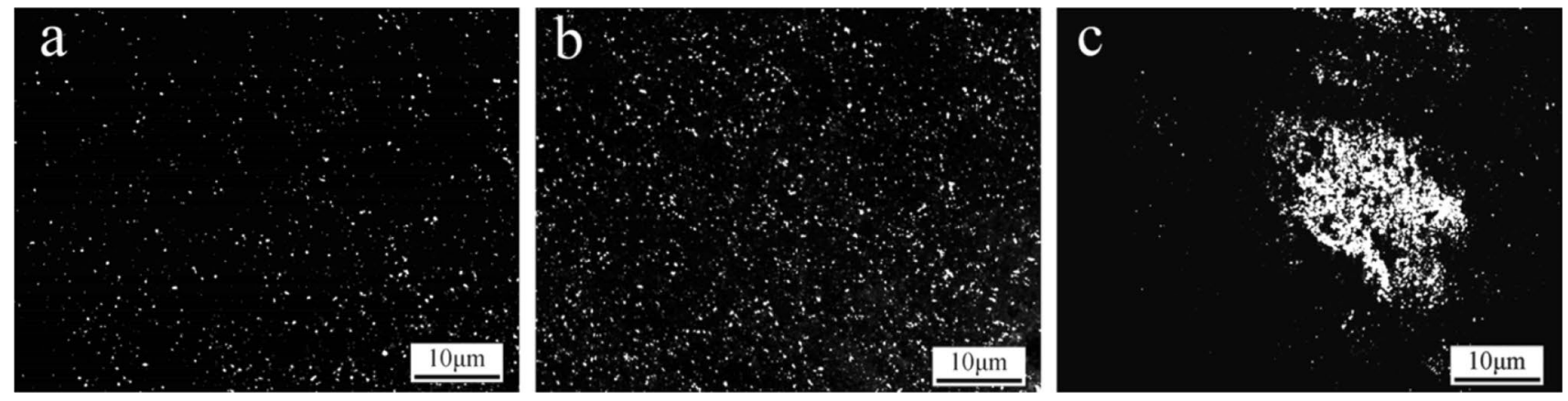

Fig. 5 TEM dark-field images of the interfacial layers after an 8-s immersion for $\mathbf{a} \operatorname{Ra}=0.455 \mu \mathrm{m}, \mathbf{b} \mathrm{Ra}=0.112 \mu \mathrm{m}$, and $\mathbf{c} \mathrm{Ra}=0.031 \mu \mathrm{m}$

volume of the smashed domain decreased when the finer polishing was applied. For sample P (Fig. 6c), the smashed domain could hardly be seen and the crystal orientation of the individual surface grain of the substrate was identical. Due to the specific crystal orientation relationship between the crystals on the substrate surface and the epitaxial $\mathrm{Fe}_{2} \mathrm{Al}_{5}$ crystals $[13,14]$, the randomly-oriented epitaxial $\mathrm{Fe}_{2} \mathrm{Al}_{5}$ interfacial layers were formed on sample $\mathrm{G} 1$ and G2. Meanwhile, the mono-orientated epitaxial $\mathrm{Fe}_{2} \mathrm{Al}_{5}$ interfacial layer was formed on sample $P$, as seen in the Fig. 5.

Figure 7 demonstrates the influence of the substrate surface roughness on the out-burst formation. The GIXRD pattern of sample $\mathrm{G} 2$ with a 60 -s immersion (Fig. 2b) shows that only the $\mathrm{Fe}_{2} \mathrm{Al}_{5}$ was detected at the interface where the out-burst already appeared. The out-burst which was characterized by an excess of discrete $\mathrm{Fe}_{2} \mathrm{Al}_{5}$ particles [10, 19] occurred in sample $G 1$ and $G 2$, but it was not shown in sample $P$. The preferential location of the out-burst formation was different between $\mathrm{G} 1$ and $\mathrm{G} 2$. The out-burst preferentially emerged along the grooves in substrate surface for sample G1 (Fig. 7a), but it appeared first in the location of the certain areas for sample G2 (Fig. 7b). For sample $\mathrm{P}$ (Fig. 7c), the $\mathrm{Fe}_{2} \mathrm{Al}_{5}$ crystals formed on the different substrate grains had a different morphology and the locations of the substrate grain boundary could be identified. The interfacial layer was gradually destroyed by the development of the Fe-Zn out-burst, which leaded to a 
Fig. 6 Crystal orientation mapping of the cross-section of the samples after an 8-s immersion for $\mathbf{a} \mathrm{Ra}=0.455 \mu \mathrm{m}$, b $R a=0.112 \mu \mathrm{m}$, and (c) $\mathrm{Ra}=0.031 \mu \mathrm{m}$
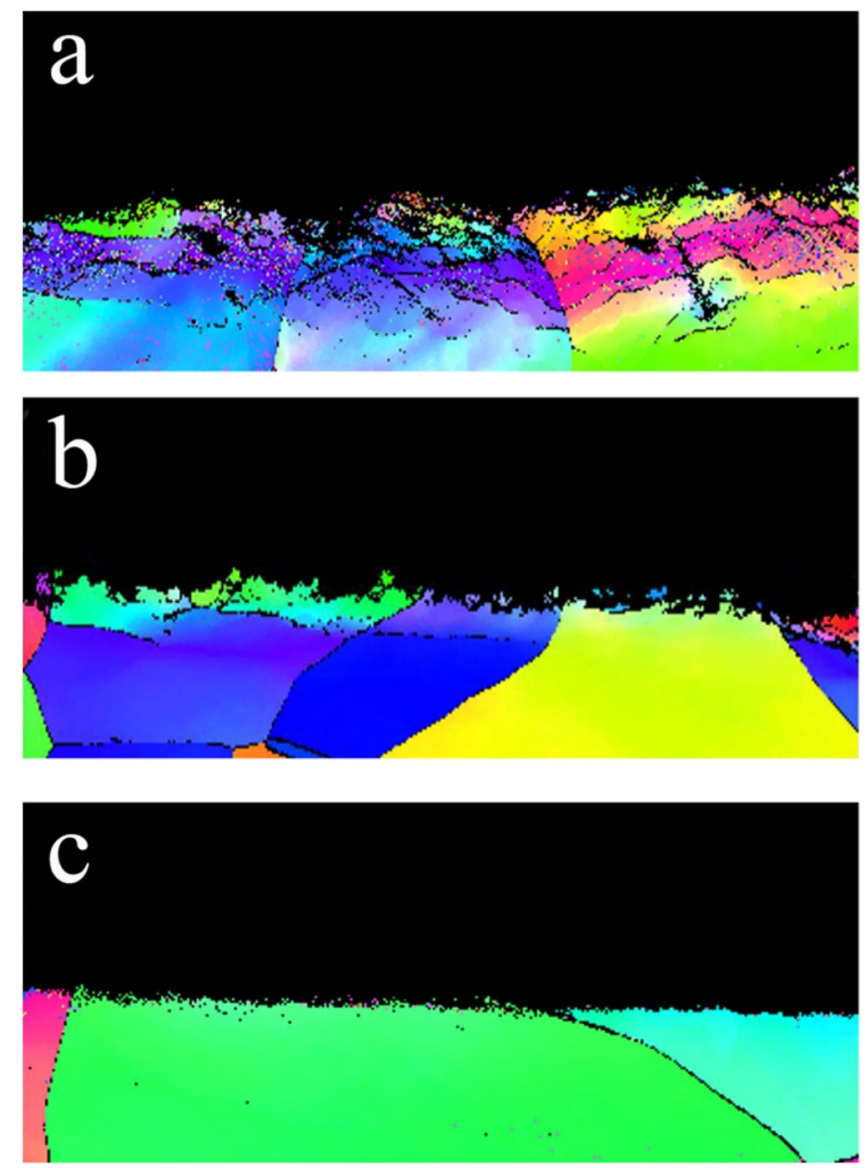

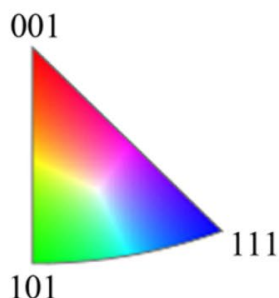

$10 \mu \mathrm{m}$
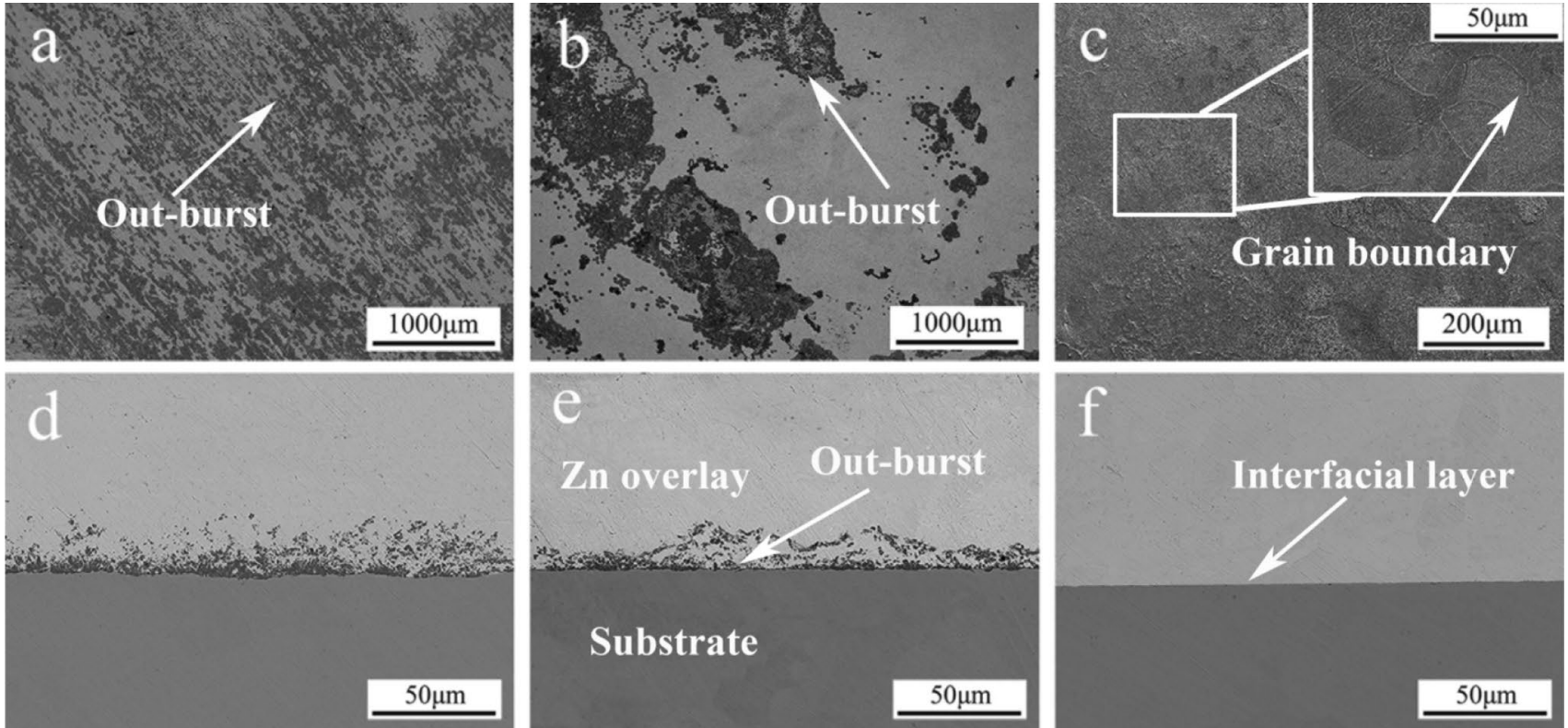

Fig. 7 Morphology of the interfacial layers after a 60-s immersion. $\mathrm{SE}$ images of the top-view of the samples with $\mathbf{a} \mathrm{Ra}=0.455 \mu \mathrm{m}$, $\mathbf{b}$ $\mathrm{Ra}=0.112 \mu \mathrm{m}$, and $\mathbf{c} \mathrm{Ra}=0.031 \mu \mathrm{m}$. BSE images of the cross-sec-

\section{SN Applied Sciences}

A SPRINGER NATURE journal tion of the samples with $\mathbf{d} R a=0.455 \mu \mathrm{m}$, e Ra $=0.112 \mu \mathrm{m}$, and $\mathbf{f}$ $\mathrm{Ra}=0.031 \mu \mathrm{m}$ 


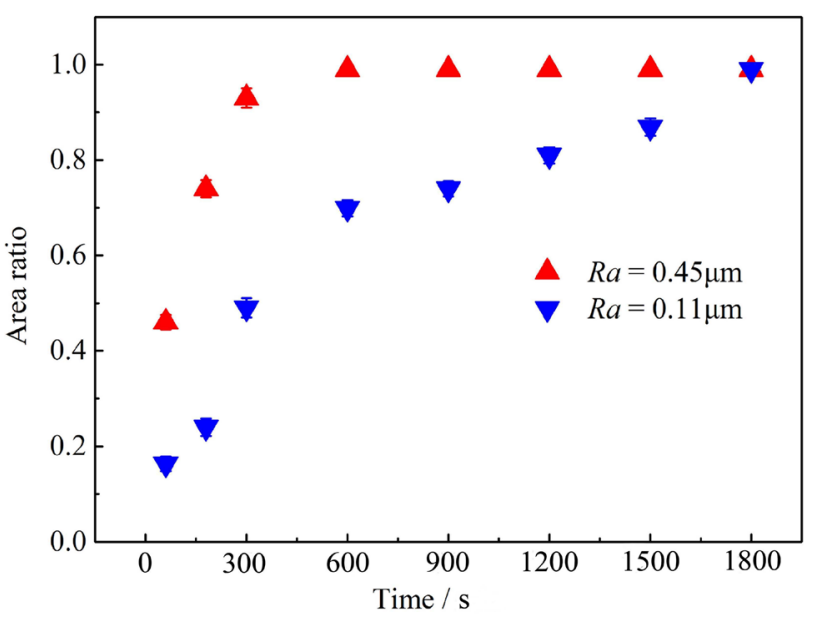

Fig. 8 Ratio of the out-burst area to the whole reaction area for $\mathrm{Ra}=0.455 \mu \mathrm{m}$ and $\mathrm{Ra}=0.112 \mu \mathrm{m}$

total breakdown for a longer immersion time [7]. The ratios of the out-burst area to the whole reaction area at different times were obtained by the image processing technique and plotted in Fig. 8. The area and the average extension rate of the out-burst of sample $\mathrm{G} 2$ were much lower than those of sample G1. The entire layer dissolved after $300 \mathrm{~s}$ for sample G1 and after 1800 s for sample G2. However, the interfacial layer of sample $P$ remained complete after an 1800-s immersion. The different behaviors of the outburst were attributed to the different morphology of the interfacial layer in the early stage of the immersion.

In this study, the surface grains of the matrix were smashed into many small and randomly-oriented crystals upon polishing and the volume of the smashed domain largely decreased when the finer polishing treatment was used. The orientation of the epitaxial $\mathrm{Fe}_{2} \mathrm{Al}_{5}$ interfacial layer became random when the surface roughness of the substrate increased $[9,13,21]$. Besides, the interfacial layers generated on the substrates with the different surface roughness had different sizes, orientation, morphology, thickness, and packing density. For sample $\mathrm{G} 1$, the $\mathrm{Fe}_{2} \mathrm{Al}_{5}$ crystals formed on the grooves were loosely packed and gaps exist among them. The gaps act as the fast diffusion paths for $\mathrm{Zn}$ which constitute the preferred out-burst formation sites, which leads to that the out-burst mainly appears along the grooves of the substrate, as seen in Fig. 7a. The small and unordered $\mathrm{Fe}_{2} \mathrm{Al}_{5}$ crystals lead to a higher percentage of high angle grain boundary in the interfacial layer [10]. The Zinc has a faster diffusion rate in the high angle grain boundary. Therefore, the average diffusion rate of Zinc in sample $\mathrm{G} 1$ is higher than those of sample $G 2$ and P. Hence, the out-burst is easily generated and expands faster in the sample $G[10,19]$, as seen in Fig. 8. In sample $G 2$, due to the interfacial layer became thicker and more compact, and the $\mathrm{Fe}_{2} \mathrm{Al}_{5}$ grain size increased, the average diffusion rate of Zinc of sample $G 2$ becomes lower. Therefore, the out-burst can be inhibited for a longer time. However, owing to the anisotropic dissolution of substrate [22], the interfacial layer is much less compact in the certain areas for the lack of Fe atoms, as seen in Fig. 4e. As the result, the Fe-Zn out-burst is preferentially generated in these locations, as seen in the Fig. $7 b$. Once the Fe-Zn out-burst appears, the Fe-Zn compounds will grow along the layer/substrate interface, peeling off the interfacial layer [23], which leads to a breakdown of the interfacial layer [7] as illustrates in Fig. 5. In sample $P$, the orientation of the compact epitaxial $\mathrm{Fe}_{2} \mathrm{Al}_{5}$ crystals formed on the same matrix grain was identical. Meanwhile, the grain size and the thickness of the interfacial layer were the largest among the test samples. Consequently, the formation of the out-burst is difficult in sample $P$ due to the low Zinc diffusion rate and the long diffusion path, as seen in Fig. 7.

\section{Conclusion}

In this study, we investigated the effect of the surface roughness on the morphology of the interfacial layer and on the out-burst formation during the hot-dip galvanizing. The values of the arithmetical mean deviation of the profile $(\mathrm{Ra})$ of the as-prepared matrixes were $0.455 \pm 0.013 \mu \mathrm{m}$, $0.112 \pm 0.011 \mu \mathrm{m}$, and $0.031 \pm 0.007 \mu \mathrm{m}$, respectively. When the surface roughness decreased, the crystal orientation of the surface grain of the substrate became more orderly. The surface roughness of the substrate had a strong influence on the morphology of the interfacial layer in the initial stage of the immersion. The thickness of the interfacial layer increased from $\sim 50$ to $\sim 140 \mathrm{~nm}$ and the layer became more compact and more orderly when the surface roughness of the substrate decreased from 0.455 to $0.031 \mu \mathrm{m}$. The morphology of the interfacial layer at the early stage of the immersion significantly affected the formation and the extension of the Fe-Zn out-burst. No out-burst formed even for an 1800-s immersion for the Ra of $0.031 \mu \mathrm{m}$ which had a thick compact orderly interfacial layer in the early stage of the immersion. However, as to Ra of $0.455 \mu \mathrm{m}$ and $0.112 \mu \mathrm{m}$, the Fe-Zn layers replaced the thin discrete randomly-distributed Fe-Al layer with a much short immersion time.

Acknowledgements This work is supported by the Science and Technology Project of Guangdong Province in China (2015B010122003, 2015B090926009), the Nature Science Foundation of Shaanxi Province of China (2018JM5002), the Guangxi Innovation Driven Development Project (GUIKEAA18242001), the Science and Technology Project of Guangzhou City in China (201604046009). We thank the Instrument Analysis Center of Xi'an Jiaotong University. 


\section{Compliance with ethical standards}

Conflict of interest The authors declared that they have no conflict of interest.

\section{References}

1. Marder AR (2000) The metallurgy of zinc-coated steel. Prog Mater Sci 45:191-271

2. Song GM, Vystavel T, van der Pers N, De Hosson JTM, Sloof WG (2012) Relation between microstructure and adhesion of hot dip galvanized zinc coatings on dual phase steel. Acta Mater 60:2973-2981

3. Okamoto NL, Kashioka D, Inomoto M, Inui H, Takebayashi $H$, Yamaguchi S (2013) Compression deformability of $\Gamma$ and $\zeta \mathrm{Fe}-$ $\mathrm{Zn}$ intermetallics to mitigate detachment of brittle intermetallic coating of galvannealed steels. Scripta Mater 69:307-310

4. Bellhouse EM, Mertens AIM, McDermid JR (2007) Development of the surface structure of TRIP steels prior to hot-dip galvanizing. Mater Sci Eng A 463:147-156

5. Harvey GJ, Mercer PD (1973) Aluminum-rich alloy layers formed during the hot dip galvanizing of low carbon steel. Metall Mater Trans A 4:619-621

6. Kato T, Nunome K, Kaneko K, Saka H (2000) Formation of the $\zeta$ phase at an interface between an Fe substrate and a molten 0.2 mass\% Al-Zn during galvannealing. Acta Mater 48:2257-2262

7. Jordan CE, Marder AR (1997) Fe-Zn phase formation in interstitial-free steels hot-dip galvanized at $450{ }^{\circ} \mathrm{C}$ : part II $0.20 \mathrm{wt} \%$ Al-Zn baths. J Mater Sci 32:5603-5610

8. Ghuman ARP, Goldstein JI (1971) Reaction mechanisms for the coatings formed during the hot dipping of iron in 0 to $10 \mathrm{Pct}$ $\mathrm{Al}-\mathrm{Zn}$ baths at $450^{\circ}$ to $700^{\circ} \mathrm{C}$. Metall Mater Trans A 2:2903-2914

9. Baril E, Lespérance G (1999) Studies of the morphology of the Al-rich interfacial layer formed during the hot dip galvanizing of steel sheet. Metall Mater Trans A 30:681-695

10. Jordan CE, Marder AR (1997) Effect of substrate grain size on iron-zinc reaction kinetics during hot-dip galvanizing. Metall Mater Trans A 28:2683-2694

11. Dutta M, Singh SB (2009) Effect of strip temperature on the formation of an $\mathrm{Fe}_{2} \mathrm{Al}_{5}$ inhibition layer during hot-dip galvanizing. Scripta Mater 60:643-646
12. Tang $\mathrm{N}-\mathrm{Y}$ (1995) Modeling Al enrichment in galvanized coatings. Metall Mater Trans A 26:1699-1704

13. Wang K-K, Chang L, Gan D, Wang H-P (2010) Heteroepitaxial growth of $\mathrm{Fe}_{2} \mathrm{Al}_{5}$ inhibition layer in hot-dip galvanizing of an interstitial-free steel. Thin Solid Films 518:1935-1942

14. Hsu C-W, Wang K-K, Chang L, Gan D, Chang Y-L, Liang H-Y, Wang $\mathrm{H}-\mathrm{P}$ (2018) Formation of $\mathrm{Fe}_{2} \mathrm{Al}_{5}-\mathrm{xZnx}$ intermetallic crystals at the $\mathrm{Fe}-\mathrm{Zn}$ interface in hot-dip galvanizing. Mater Charact 137:189-200

15. Mandal GK, Balasubramaniam R, Mehrotra SP (2009) Theoretical investigation of the interfacial reactions during hot-dip galvanizing of steel. Metall Mater Trans A 40:637-645

16. Nishimoto A, Inagaki J-I, Nakaoka K (1986) Effects of surface microstructure and chemical compositions of steels on formation of $\mathrm{Fe}-\mathrm{Zn}$ compounds during continuous galvanizing. Trans Iron Steel Inst Jpn 26:807-813

17. Chen L, Fourmentin R, McDermid JR (2008) Morphology and kinetics of interfacial layer formation during continuous hot-dip galvanizing and galvannealing. Metall Mater Trans A 39:2128

18. Morimoto Y, McDevitt E, Meshii M (1997) Characterization of the FeAl inhibition layer formed in the initial stages of hot-dip galvannealing. ISIJ Int 37:906-913

19. Jordan CE, Zuhr R, Marder AR (1997) Effect of phosphorous surface segregation on iron-zinc reaction kinetics during hot-dip galvanizing. Metall Mater Trans A 28:2695-2703

20. Wang K-K, Hsu C-W, Chang L, Gan D, Yang K-C (2013) Role of Al in $\mathrm{Zn}$ bath on the formation of the inhibition layer during hot-dip galvanizing for a $1.2 \mathrm{Si}-1.5 \mathrm{Mn}$ transformation-induced plasticity steel. Appl Surf Sci 285:458-468

21. Kawano H, Oue S, Futaba T, Kobayashi A, Goto Y, Nakano H (2018) Effect of surface textures of steel sheets on the crystal orientation of electrodeposited zinc. Tetsu-to-Hagane 104:227-234

22. Shahryari A, Szpunar JA, Omanovic S (2009) The influence of crystallographic orientation distribution on 316LVM stainless steel pitting behavior. Corros Sci 51:677-682

23. McDevitt E, Morimoto Y, Meshii M (1997) Characterization of the Fe-Al interfacial layer in a commercial hot-dip galvanized coating. ISIJ Int 37:776-782

Publisher's Note Springer Nature remains neutral with regard to jurisdictional claims in published maps and institutional affiliations. 